\title{
УДК 355.25.2
}

\section{УПРАВЛІННЯ СТРАТЕГІЧНОЮ ДІЯЛЬНІСТЮ ВІЙСЬКОВИХ ПІДРОЗДІЛІВ НАЦІОНАЛЬНОЇ ГВАРДІЇ УКРАЇНИ В РАМКАХ ЛОГІСТИЧНИХ ЛАНЦЮЖКІВ}

\author{
Герасименко В. М., ст.викладач (НАНГУ)
}

У даній статті подано методику управління стратегічною діяльністю військових підрозділів Начіональної гвардії України в рамках логістичних ланиюжсків. В роботі вказується, щзо логістичні ланџюжски мають найбільшу ефекттивність для військових підрозділів Національної гвардї̈ України внаслідок того, щэо інформачійна система військових формувань в цьому випадку виступає центральним вузлом, координуючи та інтегруючи функиії забезпечуючих систем, істотно знижуючи витрати на обслуговування ланок ланцюжка. Розглянуто загальні особливості виконання функцій системи логістики інформаційною системою військових підрозділів Національної гвардї Украӥни в логістичному ланџюжку. Здійснення логістичних прочесів військових підрозділів в рамках ланцюжка може бути представлене у вигляді запропонованої в статті багатокрокової прочедури. У пропонованій методичі припускається, щэо для кожного логістичного проекту відбирається одна компанія-претендент на партнерство в сучасному інформачійному середовищі. Таким чином, кількість потенційних партнерів покладається рівним числу логістичних проектів. У прочесі стратегічного розвитку діяльності військових підрозділів слід передбачати ітеративний повтор даної прочедури у випадку включення нових учасників у технологічний ланцюжок.

Ключові слова: логістичний ланцюжсок, військовий підрозділ, постачальник, стейкхолдери, система логістики, логістичні процеси

\section{УПРАВЛЕНИЕ СТРАТЕГИЧЕСКОЙ ДЕЯТЕЛЬНОСТИ ВОИНСКИХ ПОДРАЗДЕЛЕНИЙ НАЦИОНАЛЬНОЙ ГВАРДИИ УКРАИНЫ В РАМКАХ ЛОГИСТИЧЕСКОЙ ЦЕПОЧКИ}

\author{
Герасименко В. Н., ст.. преподаватель (НАНГУ)
}

В данной статье представлена методика управления стратегической деятельностью военных подразделений Наџиональной гвардии Украинь в рамках логистических иепочек. В работе указывается, что логистические цепочки имеют наибольшую эффективность для военных подразделений Наџиональной гвардии Украинь вследствие того, что информачионная система военных формирований в этом случае выступает иентральным узлом, координируя и интегрируя функиии обеспечиваюших систем, существенно снижая затраты на обслуживание звеньев цепочки. Рассмотрень общие особенности выполнения функций системы логистики информационной системой военных подразделений Национальной гвардии Украины в логистической чепочке. Осуществление логистических процессов военных подразделений в рамках цеепочки может быть представлено в виде предложенной в статье многомаговой процедуры. В предлагаемой методике предполагается, что для каждого логистического проекта отбирается одна компания-претендент на партнерство в современной информационной среде. Таким образом, количество потенциальных партнеров полагается равным числу логистических проектов. В процессе стратегического развития деятельности военных

(C) Герасименко В.M. 
подразделений следует предусматривать итеративный повтор данной процедуры в случае включения новых участников в технологическую цепочку.

Ключевые слова. логистическая цепочка, военное подразделение, поставщик, стейкхолдеры, система логистики, логистические процессы

\section{MANAGEMENT OF THE STRATEGIC ACTIVITY OF THE NATIONAL UNITS OF THE UKRAINE IN THE FRAMEWORK OF LOGISTIC CHAINS}

\section{Gerasimenko V., Senior Lecturer (NANGU)}

This article describes the methodology for managing the strategic activities of the military units of the National Guard of Ukraine within the logistics chains. The proposed procedure for managing the strategic activity of the military units of the National Guard of Ukraine within the logistics chains provides for the selection of strategic partners, the definition of the target guidelines of the unit within the community, the redistribution of commercial operations in the event of disruptions, coordination of management of technological chains, conflicts. In the work it is stated that logistics chains have the highest efficiency for the military units of the National Guard of Ukraine due to the fact that the information system of military formations in this case acts as a central node, coordinating and integrating the functions of the security systems, significantly reducing the cost of servicing the links of the chain. The general features of the fulfillment of the functions of the logistics system by the information system of the military units of the National Guard of Ukraine in the logistics chain are considered. The implementation of logistical processes for military units within the chain may be presented in the form of the proposed multi-step procedure. The proposed methodology assumes that for each logistical project, one applicant company is selected for a partnership in a modern information environment. Thus, the number of potential partners is equal to the number of logistics projects. In the process of strategic development of the activities of military units, iterative repetition of this procedure should be envisaged if new entrants are included in the technological chain. The further direction of research may be the development of a methodology for optimizing the logistics chains of the military units of the National Guard of Ukraine. The proposed procedure for managing the strategic activity of the military units of the National Guard of Ukraine within the logistics chains provides for the selection of strategic partners, the definition of the target guidelines of the unit within the community, the redistribution of commercial operations in the event of disruptions, coordination of technology chain management, conflicts between conflicts. In the process of strategic development of the activities of military units, iterative repetition of this procedure should be envisaged if new entrants are included in the technological chain. The further direction of research may be the development of a methodology for optimizing the logistics chains of the military units of the National Guard of Ukraine.

Key words. logistics chain, military unit, supplier, stake holders, logistics system, logistics processes

Постановка проблеми. Стрімкий розвиток інформаційних технологій спричиняе зміну стратегічних пріоритетів організацій в напрямку модернізації інформаційної системи здійснення підприємницької діяльності та розширення використання інформаційних технологій

для підтримки процесів управляння господарською діяльністю. Внаслідок таких змін компанії стають високотехнологічними, тобто такими, що мають найбільш сучасну технологічну платформу. 
У цих умовах компанії прагнуть розвиватися в руслі інших організацій, у результаті чого утворяться так звані логістичні ланцюжки. 3 позицій військових підрозділів Національної гвардії України ці логістичні ланцюжки надають можливості формування стратегічного кола постачальників і партнерів для оптимізації результатів господарської діяльності.

Аналіз останніх досліджень $\boldsymbol{i}$ публікацій. У роботах [1-4] пропонуються методологічні засади формування логістичних ланцюжків у сучасних умовах господарської діяльності. Особливості створення віртуальних організацій на основі логістичних i технологічних ланцюжків подані в дослідженнях $[5,6]$. Питання забезпечення якості інформаційних потоків в рамках сучасних логістичних розглянуто у наукових статтях [7-12].

Виділення невирішених частин загальної проблеми. Однак на сьогодні в спеціалізованій літературі відсутній методичний підхід щодо інформаційної підтримки діяльності військових підрозділів Національної гвардії України в рамках логістичних ланцюжків.

Метою даної статmi $€$ розробка методики управління стратегічною діяльністю військових підрозділів Національної гвардії України в рамках логістичних ланцюжків.

Викладення основного матеріалу дослідження. Логістичні ланцюжки мають найбільшу ефективність для військових підрозділів Національної гвардії України внаслідок того, що інформаційна система військових формувань в цьому випадку виступає центральним вузлом, координуючи та інтегруючи функції забезпечуючих систем (табл. 1 і 2), істотно знижуючи витрати на обслуговування ланок ланцюжка.

Таблиия 1

Виконання функиій системи логістики інформаційною системою військових підрозділів Наџіональної гвардї України в логістичному ланџюжску

\begin{tabular}{|l|l|l|}
\hline \multicolumn{1}{|c|}{ Система логістики } & \multicolumn{1}{|c|}{ Інформаційна система військових підрозділів } \\
\hline Складування продукції & $\begin{array}{l}\text { Зберігання інформації про «тверді» товари в електронному } \\
\text { каталозі; наяність електронних товарів і послуг на web- } \\
\text { вузлі }\end{array}$ \\
\hline $\begin{array}{l}\text { Система мережевого } \\
\text { маркетингу }\end{array}$ & Мережа Інтернет як канал розподілу товарів \\
\hline $\begin{array}{l}\text { Група посередників } \\
\text { різного рівня }\end{array}$ & $\begin{array}{l}\text { Онлайнові ринкові механізми, що здійснюють підбор } \\
\text { покупців і продавців }\end{array}$ \\
\hline $\begin{array}{l}\text { Комплекс методів } \\
\text { просування товару }\end{array}$ & $\begin{array}{l}\text { Електронне цільове маркетингове забезпечення та } \\
\text { просування товару }\end{array}$ \\
\hline
\end{tabular}

Таблиияя 2

Виконання функиій організаційної системи інформаційною системою військових підрозділів в логістичному ланцюжку

\begin{tabular}{|l|l|}
\hline \multicolumn{1}{|c|}{ Організаційна система } & \multicolumn{1}{|c|}{ Інформаційна система військових підрозділів } \\
\hline $\begin{array}{l}\text { Централізоване } \\
\text { керування ланцюжком }\end{array}$ & $\begin{array}{l}\text { Централізований web-вузол з інформацією про стратегічних } \\
\text { партнерів }\end{array}$ \\
\hline $\begin{array}{l}\text { Система моніторингу та } \\
\text { контролю }\end{array}$ & $\begin{array}{l}\text { Система безперервної фінансової звітності на web-вузлі; } \\
\text { система забезпечення безпеки електронних угод }\end{array}$ \\
\hline $\begin{array}{l}\text { Сінхронізування } \\
\text { ланцюжків } \\
\text { постачальник-споживач }\end{array}$ & $\begin{array}{l}\text { Декапіталізована компанія, що опирається на систему } \\
\text { зовнішніх виробничих структур, відносини між якими } \\
\text { грунтуються на інформації }\end{array}$ \\
\hline
\end{tabular}


Здійснення логістичних процесів військових підрозділів в рамках ланцюжка може бути представлене у вигляді багатокрокової процедури з наступних дій:

1. Вибір стратегічних партнерів за логістичним ланцюжком;

2. Визначення цільових переваг (установ) комерційної діяльності компанії в співтоваристві;

3. Забезпечення процесу перерозподілу комерційних операцій на випадок можливих збоїв у логістичному ланцюжку;

4. Координація управління логістичним ланцюжком;

5. Вирішення можливих інформаційних конфліктів між учасниками логістичного ланцюжка.

На первісному етапі планування комерційної взаємодії в рамках технологічних ланцюжків командування військового підрозділу повинно зробити вибір партнерів за стратегічним альянсом. У даній роботі такий вибір пропонується здійснювати на основі використання матричного методу прогнозування шляхом аналізу впливу компанії та можливих фірмпартнерів один на одного й на досягнення кінцевих цілей програми розвитку. У даній методиці будемо припускати, що для кожного логістичного проекту відбирається одна компанія-претендент на партнерство в сучасному інформаційному середовищі. Таким чином, кількість потенційних партнерів покладається рівним числу логістичних проектів.

Споживча спрямованість логістичного проекту може бути описана у формі матриці PN[T,M], елементами якої $\epsilon$ кількість комерційних операцій комплексу проектів М, що плануються компанією на Т-ому сегменті ринку. Для дослідження рівня маркетингових можливостей перспективних партнерів необхідно також задати матрицю VM[K,T], що відображає займану $\mathrm{K}$-ою компанією-претендентом частку ринку в Т-ому цільовому сегменті ринку. Тоді матриця-добуток CV[K,M] буде відображати рівень компетенції партнерів для реалізації комерційних операцій комплексу логістичних проектів:

$$
\mathrm{CV}[\mathrm{K}, \mathrm{M}]=\mathrm{VM}[\mathrm{K}, \mathrm{T}] \cdot \mathrm{PN}[\mathrm{T}, \mathrm{M}] \text {. }
$$

Оскільки комерційна діяльність технологічного ланцюжка певним чином повинна співвідноситися із програмою розвитку, необхідно задати також матрицюстовпець PS[M $\times 1]$ стратегічних пріоритетів компанії-партнера по логістичному проекту, охарактеризовані деякими величинами (наприклад, прибутковість, обсяг продажів). Добуток матриці PS на матрицю CV дасть матрицю-стовпець $\mathrm{G}$, що відображає вплив спільної комерційної діяльності компанії 3 K-им партнером на іiї стратегічні установи. Елементи матриці-добутку $\mathrm{G}$ визначаються за формулою:

$$
\begin{array}{ll}
\mathrm{G}[\mathrm{K} \times 1]=\mathrm{CV}[\mathrm{K}, \mathrm{M}] \cdot \mathrm{PS}[\mathrm{M} \times 1] \\
\text { i } & \text { виражають }
\end{array}
$$
співробітництва військового підрозділу з kою компанією для досягнення стратегічних цілей командування.

За результатами значень матриці $\mathrm{G}$ проводиться ранжирування та вибір партнерів за логістичним ланцюжком.

Формалізоване подання процесу здійснення комерційної взаємодії військового підрозділу в рамках логістичних ланцюжків можна представити в наступному виді. Компанія прагне досягти наступних цілей:

$$
\begin{gathered}
Q_{1}=\sum_{i=1}^{n} O S_{i} \rightarrow \max _{O S_{I}},(1) \\
Q_{2}=\sum_{i=1}^{n} R O_{i} \rightarrow \min _{R O_{I}}, \\
Q_{3}=\sum_{i=1}^{n} I B_{i} \rightarrow \max _{I B_{I}}
\end{gathered}
$$

при обмеженнях:

$$
\begin{aligned}
& \sum_{i=1}^{n} z i_{i}^{\text {вих }} \leq z i_{0} \\
& \sum_{i=1}^{n} O P_{i}^{\text {вux }} \geq O P_{0}
\end{aligned}
$$

Вісник економіки транспорту і промисловості № 69, 2020 
Критерій (1) відображає прагнення військового підрозділу максимізувати обсяг переданих зовнішнім структурам комерційних операцій (з метою зниження витрат і досягнення економічного ефекту масштабу); критерій (2) - мінімізацію ризику $\mathrm{RO}_{\mathrm{i}}$ i-ої операції, а критерій (3) ураховує бажання командування збільшувати обсяг IB релевантної інформації про бізнес-середовище мережевого співтовариства логістичних партнерів(з використанням OLAP-, ROLAPтехнологій, а також систем Data Mining, описаних в [4]). Вирази (4), (5) відображають необхідність для військового підрозділу звести вихідні обсяг витрат $z i_{i}^{\text {bux }}$ і величину обсягу продажів $O P_{i}^{\text {вux }}$ по і-ій комерційній операції до рівня не гірше деяких прийнятних величин $\mathrm{zi}_{0} \mathrm{i} \mathrm{OP}_{0}$ відповідно.

Стратегічні партнери військового підрозділу внаслідок різного роду обставин можуть давати збої при виконанні деяких 3 переданих їм комерційних операцій бізнеспроектів. Тому після відмови компаніїпартнера виконувати ту або іншу комерційну операцію в логістичному ланцюжку повинно бути передбачено перерозподіл $\mathrm{n}$ покладених на партнера функцій i виділення певної величини резервного капіталу RK для покриття пов'язаних із цим витрат.

Розподіл n комерційних операцій по $\mathrm{K}$ партнерам охарактеризуємо матрицею $\left\|\gamma_{i k}\right\|_{n \times K}$, елемент якої $\gamma_{\mathrm{ik}}=1$, якщо к-ий партнер здатний здійснити і-ту комерційну операцію; у противному випадку $\gamma_{\mathrm{ik}}=0$. У загальному виді при кратності с резервування комерційних операцій бізнеспроектів варіанти розміщення операцій відповідають матриці наступного вигляду:

$$
\left[\begin{array}{ccccc}
\mathrm{E}_{\mathrm{c} \times \mathrm{c}} & 0 & 0 & \ldots & 0 \\
0 & \mathrm{E}_{\mathrm{c} \times \mathrm{c}} & 0 & \ldots & 0 \\
0 & 0 & \mathrm{E}_{\mathrm{c} \times \mathrm{c}} & \ldots & 0 \\
\ldots & \ldots & \ldots & \ldots & \ldots \\
0 & 0 & 0 & \ldots & \mathrm{E}_{\mathrm{c} \times \mathrm{c}}
\end{array}\right](6)
$$

де $\mathrm{E}_{\mathrm{c} \times \mathrm{c}}$ - підматриці розміру $\mathrm{c} \times \mathrm{c}_{3}$ одиничних елементів. Число одиниць у кожному рядку дорівнює с; $\sum_{\mathrm{i}=1}^{\mathrm{n}} \gamma_{\mathrm{ik}}=\mathrm{c}$.

Число можливих шляхів d реалізації комерційного проекту $\mathrm{KP}=\left\{\mathrm{o}_{1}, \mathrm{o}_{2}, \ldots, \mathrm{o}_{n}\right\}$, рівне числу варіантів розподілу покладених на партнерів операцій $o_{n} \in K P$, визначається, відповідно до комбінаторного методу, як $\mathrm{d}=(\mathrm{c} !)^{\mathrm{K} / \mathrm{c}}$. Нездатність виконати комерційну операцію кожним зі стратегічних партнерів, яка відображається зміною з одиничного на нульове значення відповідного елемента матриці $\left\|\gamma_{i k}\right\|_{n \times K}$, приводить до зменшення числа можливих шляхів для розміщення (6) до $\mathrm{d}=(\mathrm{c} !)^{\mathrm{K} / \mathrm{c}-1}$.

Величину резервного капіталу RK на покриття витрат можливих збоїв у логістичному ланцюжку будемо визначати пропорційно варіантам розподілу покладених на стратегічних партнерів комерційних операцій:

$$
\mathrm{RK}=\mathrm{OZ} \cdot(\mathrm{c} !)^{\mathrm{K} / \mathrm{c}} \text {. }
$$

Висновок. Таким чином, запропонована процедура управління стратегічною діяльністю військових підрозділів Національної гвардії України в рамках логістичних ланцюжків передбачає здійснення вибору стратегічних партнерів, визначення цільових настанов підрозділу в складі співтовариства, перерозподіл комерційних операцій на випадок збоїв, координацію управління технологічним ланцюжком, вирішення можливих інформаційних конфліктів між партнерами.

У процесі стратегічного розвитку діяльності військових підрозділів слід 
передбачати ітеративний повтор даної процедури у випадку включення нових учасників у технологічний ланцюжок.

Подальшим напрямком дослідження може стати розробка методики оптимізації логістичних ланцюжків військових підрозділів Національної гвардії України.

\section{ПЕРЕЛІК ВИКОРИСТАНИХ ДЖЕРЕЛ}

1. Summary of the Methodology for assesing the Dynamics and Impacts of Electronic Commerce. OECD WPIE Ad Hoc Technucal Expert Group.2004.P.12

2. Naumenko M., Hrabovskyi Y., Elaboration of methodology for designing a publishing and printing web portal, EasternEuropean Journal of Enterprise Technologies, № $2 / 2$ (92), pp. 14 - 22, 2018. DOI: 10.15587/1729-4061.2018.126305

3. Hrabovskyi Y., Brynza N, Vilkhivska O. Development of information visualization methods for use in multimedia applications, EUREKA: Physics and Engineering. 2020. № 1, pp. 3 - 17.

4. Hrabovskyi Y., Yevsyeyev O. Development of methodological principles of support-preservation engineering work. Технолоічний аудит і резерви виробництва. 2018. №2/2. C. 43-49

5. Saabeel W., Verduijn T.M. A model of virtual organization: a structure and process perspective . Eletronic journal of organizational virtualness, 2001. V.4. № 1

6. Pushkar O., Hrabovskyi Y. Methodology for developing an intelligent user interface for educational publications in the elearning system. Development Management, № 17(3), 2019, $\quad$ P. 23-34. doi:10.21511/dm.17(3).2019.03

7. Соколовський С. А, Науменко М. О. Аналіз особливостей управління інформаційними потоками логістичних процесів підрозділів Національної гвардії України. ScienceRise. 2018. № 2. С. 19-21.

8. Науменко М.О. Вдосконалення управління якістю продукції високотехнологічних підприємств. Вісник економіки транспорту i промисловості. 2018. Випуск № 62. С. 335-342.

9. Грабовський Є. М. Аналіз використання мультимедійних компонентів в сучасних технологіях мобільного навчання. Scientific Journal «ScienceRise». 2019. № 4(57). C. 46-50

10. Каличева Н.С., Маслова В.О. Логістичні підходи, як основа раціональної організації виробничого процесу на підприємстві. Вісник економіки транспорту і промисловості. 2014. № 47. C. 83 - 86.

11. Каличева Н.С., Копачевська Ю. А. Вплив логістики на розвиток підприємств малого бізнесу в сучасних умовах господарювання. Науковий вісник УжНУ. Серія: Міжнародні економічні відносини та світове господарство. 2018. Випуск 20. Ч. 2. С. 11 - 14.

12. Каличева Н. С. Вплив інформаційних технологій на ефективність функціонування вітчизняної транспортнологістичної системи в сучасних умовах. Актуальні проблеми та напрями розвитку потенціалу соціально-економічних систем в умовах конкуренції: монографія/ за заг. редакцією д-ра екон. наук, професора Л. Л. Калініченко. Харків: ФОП Панов А.М. Видав. ТОВ «В справі», 2017. С. 201-210.

\section{REFERENCES}

1. Summary of the Methodology for assesing the Dynamics and Impacts of Electronic Commerce. (2004) OECD WPIE Ad Hoc Technucal Expert Group.P.12

2. Naumenko M., Hrabovskyi Y. (2018). Elaboration of methodology for designing a publishing and printing web portal, Eastern-European Journal of Enterprise Technologies, № 2/2 (92), pp. 14 - 22. DOI: 10.15587/1729-4061.2018.126305

3. Hrabovskyi Y., Brynza N, Vilkhivska O. (2020).Development of information visualization methods for use in multimedia applications, EUREKA: Physics and Engineering. № 1, pp. 3 - 17. 
4. Hrabovskyi Y. Yevsyeyev O. (2018). Development of methodological principles of support-preservation engineering work Technological audit and production reserves. №2/2. C. 43-49.

5. Saabeel W., Verduijn T.M. (2001)A model of virtual organization: a structure and process perspective . Eletronic journal of organizational virtualness, V.4. № 1

6. Pushkar O., Hrabovskyi Y. (2019). Methodology for developing an intelligent user interface for educational publications in the elearning system. Development Management, № 17(3). P.

23-34. doi:10.21511/dm.17(3).2019.03

7. Sokolovskyi S. A., Naumenko N. A. (2018). Analiz osobly`vostej upravlinnya informacijny`my` potokamy` logisty`chny'x procesiv pidrozdiliv Nacional noyi gvardiyi Ukrayiny. [Analysis of peculiarities of management of information flows of logistic processes of units of the National Guard of Ukraine]. ScienceRise. No 2, pp. 19-21.

8. Naumenko M. O. (2018). Vdoskonalennya upravlinnya yakistyu produkciyi vy`sokotexnologichny`x pidpry yemstv. [Improvement of product quality management of high-tech enterprises. Bulletin of the Economics of Transport and Industry. No. 62, pp. $335-342$.

9. Hrabovskyi Y. M. (2019). Analiz vy`kory`stannya mul’ty`medijny`x komponentiv $\mathrm{v}$ suchasny` $\mathrm{x}$ texnologiyax mobil'nogo navchannya. [Analysis of the use of multimedia components in modern technologies of mobile learning]. Scientific Journal "ScienceRise". No. 4 (57), pp. 46-50.

10. Kalycheva N.Ie., Maslova V.O. (2014) Lohistychni pidkhody, yak osnova ratsionalnoi orhanizatsii vyrobnychoho protsesu na pidpryiemstvi [Logistic approaches as a basis for rational organization of production process at the enterprise]. Bulletin of Economics of Transport and Industry. No. 47. Pp. 83 - 86.

11. Kalycheva N.Ie., Kopachevska Yu. A. (2018) Vplyv lohistyky na rozvytok pidpryiemstv maloho biznesu $\mathrm{v}$ suchasnykh umovakh hospodariuvannia. [The influence of logistics on the development of small business in modern conditions of management]. $U z h N U$ Scientific Bulletin. Series: International Economic Relations and the World Economy. Issue 20. Part 2. Pp. 11 - 14.

12. Kalicheva N. E. (2017). Vply`v informacijny`x texnologij na efekty`vnist` funkcionuvannya vitchy`znyanoyi transportnologisty`chnoyi sy`stemy` v suchasny`x umovax. [Influence of information technologies on efficiency of functioning of domestic transport-logistic system in modern conditions]. Aktual `ni problemy` ta napryamy` rozvy`tku potencialu social`no-ekonomichny`x sy`stem v umovax konkurenciyi: monografiya. [Actual problems and directions of development of potential of socio-economic systems in the conditions of competition: monograph]. Kharkiv: FOP Panov AM Issued. LLC In Business, pp. 201-210. (in Ukrainian)

\title{
УДК 004.15.2
}

\section{РОЗРОБКА ІНФОРМАЦЙНОЇ ПІДТРИМКИ ПРОЦЕСІВ УПРАВЛІННЯ ВНУТРІШНІМ АУДИТОМ ВІЙСЬКОВИХ ПІДРОЗДІЛІВ НАЦІОНАЛЬНОЇ ГВАРДІЇ УКРАЇНИ}

\author{
Науменко М.О., професор (НАНГУ)
}

У даній статті подано аналіз систем інформаџійної підтримки процесів управління внутрішнім аудитом формувань Начіональної гвардї Украӥни. У якості конщептуальної основи інформаційної підтримки внутрішнього аудиту формувань 